\title{
Propranolol for management of Infantile Haemangioma: A Single Centre Experience
}

\author{
Singh $\mathbf{N}^{1}$, Rohit $\mathrm{D}^{2}$, Singh $\mathrm{S}^{3}$, Thakur $\mathrm{O}^{4}$ Verma $\mathbf{R S}^{5}$ \\ ${ }^{1}$ Dr Nagendra Singh, Assistant Professor, Department of surgery, ${ }^{2}$ Dr Dushyant Rohit, Associate Professor, Department of \\ surgery, ${ }^{3}$ Dr.Sona Singh, Assistant Professor, Department of Obstetrics \& Gynaecology, ${ }^{4}$ Dr Omkar Thakur, Senior \\ Resident Department of surgery, ${ }^{5}$ Dr R S Verma, Professor and Head, Department of surgery. All are affiliated with \\ Bundelkhand Medical College Sagar, MP, India.
}

Address for Correspondence: Dr. Nagendra Singh, Email: drnagendra.804@gmail.com

\begin{abstract}
Objective: Infantile hemangiomas are the most common benign tumour in infancy. Propranolol has recently been introduced as therapeutic agent for treating hemangiomas. This study explores the impact of Propranolol on hemangiomas. Study Design: Prospective study. Materials and Methods: Propranolol was given to 32 children (19 girls and 13 boys) having hemangiomas between age of 3 weeks to 12 months at a dose of $2 \mathrm{mg} / \mathrm{kg}$ per day, in 2 or 3 divided doses. Total duration of study period was one year from July 2013 to June 2014. Serial photographs were taken at 4-6 weeks interval during the course of their therapy to record clinical response. Results: out of 32 patients 31 patients showed improvement in their hemangiomas by reduction in size and change in color during propranolol therapy. Results were determined as complete resolution (n- 5, 15.6\%), ongoing resolution (n-26, 81.2\%). No side effects of propranolol were observed in any patient. Conclusions: Propranolol appears to be a valuable and effective treatment option for infantile hemangiomas. Propranolol is likely to revolutionize the treatment of hemangiomas.
\end{abstract}

Keywords: Propranolol, Hemangioma, Beta-Blocker.

\section{Introduction}

Infantile hemangiomas (IHs) are the most-common softtissue tumors of infancy, occurring in $4 \%$ to $10 \%$ of children less than1 year of age, with a clear female predominance (female/male ratio: 2.5-4:1). Because of this benign, self-limited course, therapeutic abstention is the rule. In approximately $10 \%$ of IHs which may be life-threatening locations, local complications, and cosmetic risks require treatment [1].

Local complications such as haemorrhage, ulceration, and necrosis can be very painful and may lead to scars that are difficult to repair.

IHs in some locations can impair sensory functions; for example, IHs of the upper eyelid can induce anisometropia, astigmatism, and amblyopia. In addition, IHs causes transient cosmetic disfigurement, which likely to trigger psychological morbidity first in parents and later in affected children $[1,2]$.

Manuscript received: $29^{\text {th }}$ Nov 2014

Reviewed: $6^{\text {th }}$ Dec Aug 2014

Author Corrected: $14^{\text {th }}$ Dec 2014

Accepted for Publication: $4^{\text {th }}$ Jan 2015
Hemangiomas that usually require treatment, those are involving the periorbital area, central face, airway, skin folds, and anogenital area. These sites are at high risk for ulceration, dysfunction, or disfigurement [3].

Current treatment options for problematic hemangiomas are systemic or intralesional corticosteroids, chemotherapeutic agents (alpha-interferon, vincristin), laser, surgery, or a combination of these therapies [4].

Unfortunately, each treatment option has limited therapeutic benefit with its own side-effect profile and risks. Recently, Leaute-Labreze and colleagues reported the serendipitous finding that hemangiomas regress in newborns treated with propranolol, a known nonselective beta-blocker used in treating infants with cardiac and pulmonary conditions [5] Similar finding has also been observed in few case reports $[6,8]$.

Few cases have also been reported that hemangiomas regress rapidly when treated with Propranolol at a therapeutic dose of $2 \mathrm{mg} / \mathrm{kg} /$ day $[5,6]$. 
Research Article

In this study, we have explored the impact of Propranolol on infantile hemangiomas which interfere with normal function and cosmetic development at our centre.

\section{Materials and Methods}

This study was conducted in the department of surgerybundelkhand medical college and hospital sagar (M.P). Study was permitted by institutional ethical committee. This is a prospective study. Total 32 patients from 3 weeks to 12 months of age with 19 girls and 13 boys were taken in this study. The study period was between July 2013 to June 20114. Detail clinical examination including site and size of lesion were noted. History of previous treatment with steroid or other medication was taken. Contraindication for Propranolol (e.g. bronchial asthma, hypoglycemia, gastro-esophageal reflux etc) were recorded and such children were excluded from the study. Three babies had received oral prednisolone in the first and second months of their life, but without any clinical improvement were also included in the study.

An oral propranolol was given to all patients in a dose of $2 \mathrm{mg} / \mathrm{kg}$ /day divided into 2-3 doses was deemed safe and potentially effective as determined by LeauteLabreze and colleagues [5]. To record the response of Propranolol serial photographs were taken. First photograph was taken before or at the time of starting treatment with Propranolol and then every 4-6 weeks interval to record the response of Propranolol. Doses were adjusted as the child grows by taking regular body weight of the child. Propranolol is weaned at the end of treatment, by reducing the dose to one half for 1 to 2 weeks, then stopped $[9,10]$. Parents were asked to tell us about any side effects of treatment and overall satisfaction about propranolol treatment. Hemangiomas were rated as complete resolution with apparently no residual disease, ongoing resolution with residual disease requiring adjuvant treatment and nonresponder with no sign of resolution depending on the response of the lesion to Propranolol treatment.

\section{Results}

Total 32 patients with hemangioma were treated with oral Propranolol. Five out of 32 patients (15.6\%) had complete resolution with apparently no residual disease. Average time for complete resolution was 4 months in these cases. Twenty six patients $(81.2 \%)$ showed progressive reduction in size and color of their hemangiomas. These patients were considered to be partial responders and are on ongoing Propranolol therapy. Only one patient had persistent hemangioma growth despite Propranolol therapy for 4 months and was termed nonresponder.

Serial photographs of patients were taken during the course of their treatment with oral Propranolol [Fig $1 \&$ 2]. Earliest response was observed within 4 weeks of therapy and most of the patients start showing visual response within 6 weeks of starting therapy. In this study it is also observed that lesions which respond to therapy earlier show complete resolution earlier. No side effects were reported during study.

Table No 1: Response of Treatment with Propranolol

\begin{tabular}{|l|l|l|}
\hline S No & Response of treatment & Number (percentage) \\
\hline 1 & Complete Resolution & $5(15.6 \%)$ \\
\hline 2 & Partial resolution & $26(81 \%)$ \\
\hline 3 & No Response & 01 \\
\hline
\end{tabular}

\section{Discussion}

Hemangiomas are the most common benign tumor in infancy [11,12]. Although the majority have little impact on childhood health, various problematic head and neck hemangiomas will develop rapidly and interfere with normal function and appearance. These problematic hemangiomas require intervention to control growth and reduce the likelihood of imminent functional and cosmetic deformities.

Propranolol was recently found to lighten and reduce the size of hemangiomas [5]. Exact mechanism of action and pathophysiology behind this discovery remains unclear.

Theories suggesting that propranolol impacts hemangioma growth through the induction of apoptosis and antiangiogenic activity are gaining support. Nevertheless, several case studies have further provided evidence of the dramatic effect of propranolol on massive, proliferating, life threatening, and involuting lesions $[6,7,8]$. Since the introduction of 

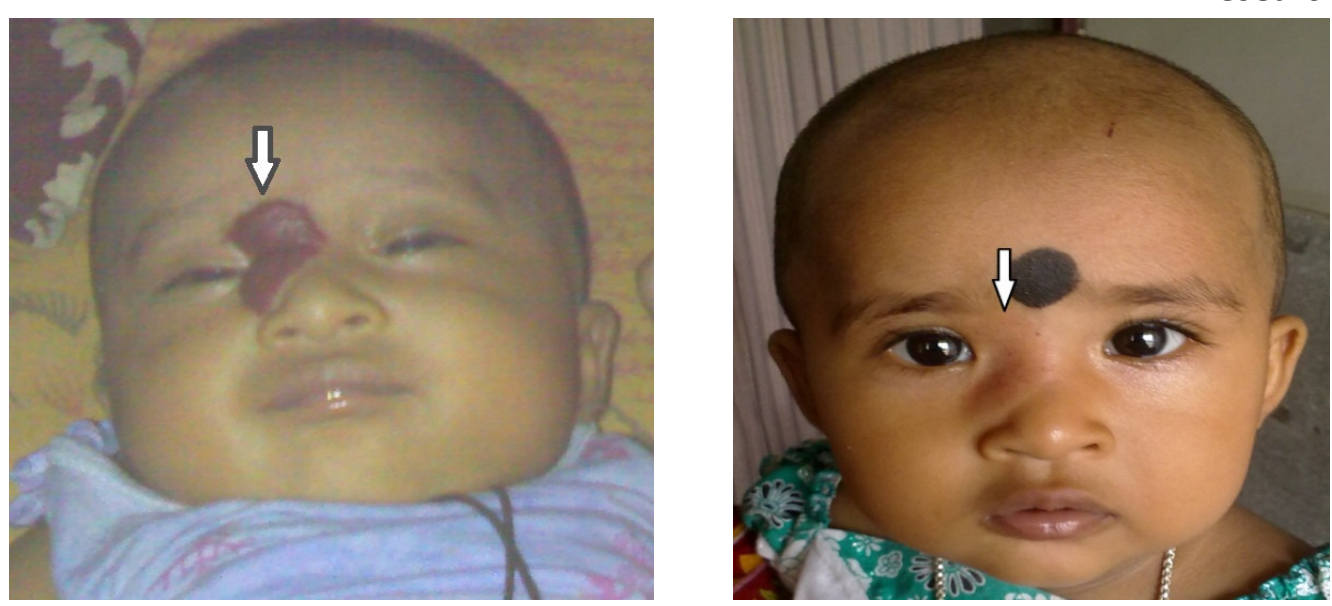

Fig 1: Hemangioma before and after the treatment with propranolol
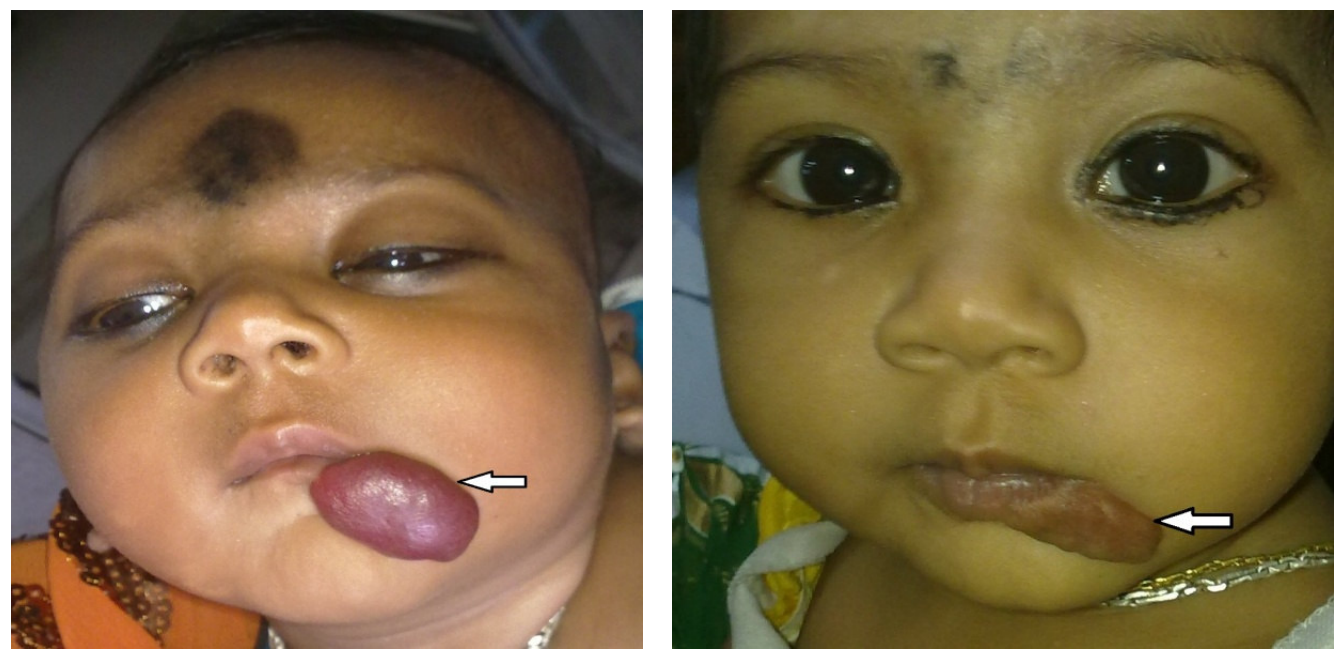

Fig 2: Hemangioma before and after the treatment with propranolol

Propranolol as a treatment option for problematic hemangiomas, our center offered this therapy for offlabel use to help manage over 32 children with these lesions. Current treatment options for complicated hemangiomas include various medical or surgical modalities. The mainstay of treatment recently for infantile hemangiomas was corticosteroids, including topical, intralesional, and oral formulations, the most common being oral prednisolone. Other treatment modalities for hemangiomas are chemotherapeutic agents (interferon-alpha, vincristin), laser therapy, surgery or combinations of these are used in complicated and refractory hemangioma $[13,14,15]$.

Whilst steroids are effective, the liable complications of steroids, including: gastric upset, Cushing's syndrome, and growth retardation [16]. Intralesional steroid for periorbital lesions could cause central retinal artery occlusion and even eyelid necrosis [10, 17]. Since the introduction of Propranolol as a treatment option for hemangiomas, our center offered this therapy to 32 children with hemangiomatic lesions comes to our institute. Propranolol is a nonselective beta-blocker and use in congenital cardiac anomalies. Its vasoconstrictive property results in reduction in color and size of hemangioma. Its primary effect however, likely to be alteration in the progression of angiogenesis in the hemangioma. Regulation of growth of hemangioma involves basic fibroblast growth factor (bFGF) and vascular endothelial growth factor (VEGF).

Léauté-Labréze and colleagues suggested that propranolol may decrease expression of bFGF and VEGF. Truong and colleagues have also proposed that beta-adrenergic antagonists may ablate catecholamine receptor signaling, decreasing cyclic AMP and reducing the levels of VEGF.

In addition, by triggering apoptosis in endothelial cells propranolol may promote involution of

hemangiomas $[5,18]$. 


\section{Adverse Effects}

Treatment with oral propranolol has been well tolerated in most of the cases of infantile hemangioma published to date. Somnolence, hypotension, bradycardia, bronchospasm, and hypoglycemia are the primary adverse effects reported with propranolol use in infants[19]. These reactions typically respond to dose reduction and may not require discontinuation of therapy. No side effect observed in our study.

\section{Dosing Recommendations}

Treatment protocols for oral propranolol in infantile hemangiomas were first described by Siegfried, Keenan, and Al-Jurcidini [20]. On their recommendations General treatment guidelines have been developed and used by subsequent authors [5,21-23].

Therapy is initiated with oral propranolol dose of 0.5-1 $\mathrm{mg} / \mathrm{kg}$ /day (divided into three times daily). If no any side effects observed, the dose may be increased to 2-3 $\mathrm{mg} / \mathrm{kg} /$ day. Treatment is continued for 6-12 months, with doses adjusted according to weight gain on a monthly basis. The general recommendation for tapered off of propranolol is $50 \%$ reduction in dose for $1-2$ weeks prior to discontinuation. Based upon the above study, oral Propranolol treatment with $2 \mathrm{mg} / \mathrm{kg} /$ day is also started in our centre which is safe and effective.

Buckmiller et al, treated 41 cases with 39\% excellent responders, $36 \%$ partial responder and $2.5 \%$ were nonresponder [24]. Similarly Qin et al. conducted therapy in 58 patients; out of which, $17 \%$ were excellent responders, $60 \%$ had good response, $20 \%$ had moderate response and $1.7 \%$ were non-responders [25]. In our prospective study, we found that out of 32 patients 15.6 $\%$ (n-5) had complete resolution 81.2\% (n-26) had partial responder and $3.1 \%(n-1)$ was non-responder.

\section{Conclusions}

Based on the successful results of our study and few others, Propranolol is likely to be a safe and effective treatment option for hemangiomas at therapeutic doses ( $2 \mathrm{mg} / \mathrm{kg} /$ day). Although, more comparative, randomized studies with a greater number of patients are needed to confirm the safety and efficacy of the drug.

Funding: Nil

Permission from IRB: Yes

Conflicts of interest: The authors report no conflicts of interest

\section{References}

1. Frieden IJ, Haggstrom A, Drolet BA, et al. Infantile hemangiomas: current knowledge, future directions: proceedings of a research workshop on infantile hemangiomas. Pediatr Dermatol. 2005;22(5):383- 406

2. Tanner JL, Dechert MP, Frieden IJ. Growing up with a facial hemangioma: parent and child coping and adaptation. Pediatrics. 1998;101(3):446-452

3. Haggstrom AN, Drolet BA, Baselga E, et al. Prospective study of infantile hemangiomas: clinical characteristics predicting complications and treatment. Pediatrics. 2006 Sep;118(3):882-7.

4. Fawcett SL, Grant I, Hall PN, Kelsall AW, Nicholson JC. Vincristine as a treatment for a large haemangioma threatening vital functions. Br J Plast Surg. 2004 Mar;57(2):168-71.

5. Leaute-Labreze C, Dumas de la Roque E, Hubiche T, Boralevi F, Thambo JB, Taieb A. Propranolol for severe hemangiomas of infancy. N Engl J Med. 2008 Jun 12;358(24):2649-51. doi: 10.1056/NEJMc0708819.

6. Buckmiller L, Dyamenahalli U, Richter GT. Propranolol for airway hemangiomas: case report of novel treatment. Laryngoscope. 2009 Oct;119(10):20514. doi: 10.1002/lary.20633.

7. Theletsane $\mathrm{T}$, Redfern A, Raynham $\mathrm{O}$, Harris $\mathrm{T}$, Prose NS, Khumalo NP. Life-threatening infantile haemangioma: a dramatic response to propranolol. J Eur Acad Dermatol Venereol. 2009 Dec;23(12):1465-6. doi: 10.1111/j.1468-3083.2009.03261.x. Epub 2009 May 6.

8. Denoyelle F, Leboulanger N, Enjolras O, Harris R, Roger G, Garabedian EN. Role of Propranolol in the therapeutic strategy of infantile laryngotracheal hemangioma. Int J Pediatr Otorhinolaryngol2009;73:1168-1172.

9. The Laryngoscope VC 2010 The American Laryngological, Rhinological and Otological Society, Inc. Propranolol for Infantile Hemangiomas: Early Experience at a Tertiary Vascular Anomalies Center,

Lisa M. Buckmiller, MD; Patrick D. Munson, MD; Umesh Dyamenahalli, MD; Yuemeng Dai, MD, PhD; Gresham T. Richter, MD. Available at : onlinelibrary.wiley.com/doi/10.1002/lary.20807/pdf cited on $20^{\text {th }}$ December 2014. 
Research Article

10. Sutula FC, Glover AT. Eyelid necrosis following intralesional corticosteroid injection for capillary hemangioma. Ophthalmic Surg. 1987 Feb;18(2):103-5.

11. Haggstrom AN, Drolet BA, Baselga E, et al. Prospective study of infantile hemangiomas: demographic, prenatal, and perinatal characteristics. J Pediatr. 2007 Mar;150(3):291-4..

12. Mulliken JB, Glowacki J. Classification of pediatric vascular lesions. Plast Reconstr Surg. 1982 Jul;70(1):120-1.

13. Frieden IJ, Eichenfield LF, Esterly NB, Geronemus R, Mallory SB. Guidelines of care for hemangiomas of infancy. American Academy of Dermatology Guidelines/Outcomes Committee. J Am Acad Dermatol. 1997 Oct;37(4):631-7.

14. Bennett ML, Fleischer AB Jr, Chamlin SL, Frieden IJ. Oral corticosteroid use is effective for cutaneous hemangiomas: an evidence-based evaluation. Arch Dermatol. 2001 Sep;137(9):1208-13.

15. Dinehart SM, Kincannon J, Geronemus R. Hemangiomas: evaluation and treatment. Dermatol Surg. 2001 May;27(5):475-85.

16. Boon LM, MacDonald DM, Mulliken JB. Complications of systemic corticosteroid therapy for problematic hemangioma. Plast Reconstr Surg. 1999 Nov;104(6):1616-23.

17. Shorr N, Seiff SR. Central retinal artery occlusion associated with periocular corticosteroid injection for juvenile hemangioma. Ophthalmic Surg. 1986 Apr;17(4):229-31.

18. Truong MT, Chang KW, Berk DR, et al. Propranolol for the treatment of a life-threatening subglottic and mediastinal infantile hemangioma. J Pediatr. 2010 Feb;156(2):335-8. doi: 10.1016/j.jpeds.2009.10.010.

19. Zimmermann AP, Wiegand S, Werner JA, et al. Propranolol therapy for infantile haemangiomas: review of the literature. Int J Pediatr Otorhinolaryngol. 2010 Apr;74(4):338-42. doi: 10.1016/j.ijporl.2010.01.001. Epub 2010 Feb 1.

20. Siegfried EC, Keenan WJ, Al-Jureidini S. More on propranolol for hemangiomas of infants [letter]. N Engl J Med. 2008 Dec 25;359(26):2846; author reply 2846-7. doi: 10.1056/NEJMc086443.

21. Bonifazi E, Mazzotta F, Balduci G, et al. Propranolol in rapidly growing hemangiomas. Eur $\mathrm{J}$ Pediatr Dermatol 2008;18:185-92.

22. Sans V, Dumas de la Roque E, Berge J, et al. Propranolol for severe infantile hemangiomas: followup report. Pediatrics. 2009 Sep;124(3):e423-31. doi: 10.1542/peds.2008-3458. Epub 2009 Aug 10.

23. Lawley LP, Siegfried E, Todd JL. Propranolol treatment for hemangioma of infancy: risks and recommendations. Pediatr Dermatol. 2009 SepOct;26(5):610-4. doi: 10.1111/j.1525-1470.2009. 00975.x.

24. Buckmiller LM, Munson PD, Dyamenahalli U, Dai Y, Richter GT. Propranolol for infantile hemangiomas: Early experience at a tertiary vascular anomalies center. Laryngoscope. 2010 Apr;120(4):676-81. doi: 10.1002/lary.20807.

25. Qin ZP, Liu XJ, Li KL, Zhou Q, Yang XJ, Zheng JW. Treatment of infantile hemangiomas with low-dose propranolol: Evaluation of short-term efficacy and safety. Zhonghua Yi Xue Za Zhi. 2009 Dec $1 ; 89(44): 3130-4$.

\section{How to cite this article?}

Singh N, Rohit D, Singh S, Thakur O, Verma RS. Propranolol for management of Infantile Haemangioma: A Single Centre Experience. Int J Med Res Rev 2015;3(1):40-44. doi:10.17511/ijmrr.2015.i1.25 